\title{
Minat Mahasiswa Akuntansi Feb UKSW untuk Mengikuti Ujian Sertifikasi Chartered Accountant (CA)
}

\author{
Dwi Arif Kurniawan1, Paskah Ika Nugroho² \\ 1,2 Universitas Kristen Satya Wacana, Salatiga, Indonesia
}

\begin{abstract}
Keywords:

Student Interest;

Chartered

Accountant

Certification

Abstract: The accounting profession of students is caused by the stereotype of the accounting profession, so students can see that the accounting profession is a less interesting and boring profession, because people think that accounting is always associated with numbers and rules. The purpose of this study was to analyze the interest of accounting students to take the Chartered Accountant (CA) exam in terms of tuition fees, gender, study program accreditation status, and IAI membership card. The population of this study were students of the accounting study program, Faculty of Economics and Business. The data in this study were obtained through the distribution of questionnaires to 100 accounting student respondents. The use of data analysis in this study using multiple linear regression method. Furthermore, to test the hypothesis using a partial significance test (T-test) and simultaneous significance test (F-test). The results of the analysis of the Ttest in this study partially show that the cost of education and the accreditation status of the study program have an effect on the interest of accounting students to take the CA certification exam, while gender and IAI membership card have no effect on the interest of accounting students to take the CA certification exam. However, the F-test results show that simultaneously the cost of education, gender, study program accreditation status and membership card affect the interest of accounting students to take the CA certification exam. The implications of this research are expected to attract students to take the chartered accountant certification exam.
\end{abstract}

\section{Kata kunci:}

Minat Mahasiswa;

Sertifikasi

Chartered

Accountant

\begin{abstract}
Abstrak: Profesi akuntansi mahasiswa disebabkan oleh stereotipe profesi akuntansi, sehingga mahasiswa dapat melihat bahwa profesi akuntansi merupakan profesi yang kurang menarik dan membosankan. Orang menganggap akuntansi selalu dikaitkan dengan angka dan kaidah. Tujuan penelitian ini adalah untuk menganalisis minat mahasiswa akuntansi untuk mengikuti ujian Chartered Accountant (CA) yang ditinjau dari biaya pendidikan, jenis kelamin, status akreditasi program studi, dan kartu anggota IAI. Populasi penelitian ini adalah mahasiswa program studi akuntansi Fakultas Ekonomika dan Bisnis. Data dalam penelitian ini diperoleh melalui penyebaran angket kuesioner kepada 100 responden mahasiswa akuntansi. Analisis data dalam penelitian ini menggunakan metode regresi linier berganda. Untuk pengujian hipotesis digunakan uji signifikansi parsial (uji-T) dan uji signifikansi simultan (uji-F). Hasil analisis dari uji-T dalam penelitian ini secara parsial menunjukkan jika biaya pendidikan dan status akreditasi program studi memiliki pengaruh terhadap minat mahasiswa akuntansi untuk mengikuti ujian sertifikasi CA, sedangkan jenis kelamin dan kartu anggota IAI tidak berpengaruh terhadap minat mahasiswa akuntansi untuk mengikuti ujian sertifikasi CA. Hasil uji-F menunjukkan bahwa secara simultan biaya pendidikan, jenis kelamin, status akreditasi program studi, dan kartu anggota memengaruhi minat mahasiswa akuntansi untuk mengikuti ujian sertifikasi CA. Implikasi penelitian ini diharapkan dapat menarik minat mahasiswa untuk mengikuti ujian sertifikasi chartered accountant.
\end{abstract}

Alamat Korespondensi:

E-mail: 232020703@student.uksw.edu (Kurniawan)

$\begin{array}{ll}\text { History: } & \\ \text { Received } & \text { : 20 April } 2021 \\ \text { Revised } & : 23 \text { April } 2021 \\ \text { Accepted } & \text { : 07 Juli } 2021 \\ \text { Published } & \text { : 25 Juli } 2021\end{array}$

History:

Received

Accepted

Published
23 April 2021

:25 Juli 2021
Publisher: Undiksha Press

Licensed: This work is licensed under a Creative Commons Attribution 3.0 License

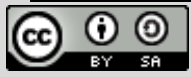




\section{Pendahuluan}

Dunia bisnis terus berkembang, dan profesi akuntan tidak dapat terpisahkan. Untuk memenuhi permintaan perusahaan akan jasa akuntansi, pendidikan profesional akuntansi diperlukan untuk melatih lulusan akuntan profesional bersertifikat. Akuntan akan bersaing dalam mengembangkan passion dalam pekerjaan (Widyanto \& Fitriana, 2016). Oleh karena itu, akuntan harus meningkatkan kualitas dan kemampuannya sendiri agar dapat disebut sebagai akuntan profesional dan dapat bersaing dengan akuntan lainnya. Salah satu peluang untuk memperoleh sertifikasi bagi lulusan akuntansi adalah dengan memperoleh sertifikat akuntan dengan gelar CA, yang dapat diperoleh melalui ujian sertifikasi yang disebut CA (Chartered Accountant) (Gretha Steenkamp, 2014; Setyawan \& Iswanaji, 2019b). Chartered accountant (CA) adalah akuntan profesional yang bertanggung jawab menyusun dan melaporkan laporan keuangan kepada pemegang saham dan publik (IAI, 2019). Bagi akuntan yang ingin memperoleh gelar Chartered Accountant harus mengikuti ujian yang diselenggarakan oleh IAI dengan membayar biaya-biaya administrasi seperti biaya pendaftaran, iuran keanggotan, dan biaya ujian. Selain itu, calon penerima gelar Chartered Accountant juga minimal telah memiliki pengalaman kerja di bidang akuntansi minimal 3 tahun atau 2 tahun untuk seseorang yang telah menyelesaikan pendidikan profesi akuntansi, magister, atau doktor yang menekankan penerapan praktik-praktik di bidang akuntansi (Setyawan dan Iswanaji, 2019).

Perkembangan profesi akuntan saat ini sejalan dengan semakin banyaknya tuntutan akuntan. Sayangnya perbandingan jumlah akuntan dengan kebutuhan dunia kerja masih belum seimbang, terutama akuntan bergelar CA karena pertumbuhan akuntan bergelar CA di Indonesia masih lambat. Dalam penelitian Nisa (2019) menjelaskan bahwa Kota Medan memiliki 970 siswa pada tahun 2016, 633 siswa pada tahun 2017, dan 728 siswa pada tahun 2018. Di antaranya, pada 2017 angka ini turun $34,7 \%$, sedangkan jumlah lulusan pada 2018 meningkat 15,0\%. Namun, sejak tiga tahun terakhir jumlah lulusan akuntansi tahun 2016-2018 mengalami penurunan dengan skor rata-rata 24,85\%. Hal ini menunjukkan bahwa minat mahasiswa dalam mempelajari akuntansi masih rendah dan persyaratan untuk menjadi akuntan bergelar CA semakin menurun. Pada tahun 2018 jumlah peserta dari Sumatera Utara yang mengikuti ujian CA berjumlah 4 orang dan hanya satu orang yang berhasil lulus 7 mata ujian CA. Pada saat yang sama, yang lainnya belum menyelesaikan ketujuh mata pelajaran yang dijadwalkan. Saat ini, terdapat 580 akuntan bergelar CA di Sumatera Utara). Angka tersebut masih jauh dari perkiraan sebelumnya. Tentunya akuntan memegang peranan penting dalam mencapai pembangunan berkelanjutan karena perekonomian nasional yang bersih dan efisien harus memenuhi prinsip keterbukaan dan akuntabilitas keuangan (Prayitno, 2021; Widyanto \& Fitriana, 2016) (Widyanto dan Fitriana, 2016). Dalam penelitian Nisa (2019) menunjukkan bahwa daya tarik akuntan Indonesia semakin menurun. Profesi akuntansi mahasiswa disebabkan oleh stereotipe profesi akuntansi, sehingga mahasiswa melihat bahwa profesi akuntansi merupakan profesi yang kurang menarik dan membosankan karena orang menganggap akuntansi selalu dikaitkan dengan angka dan kaidah (Mongilala, 2021; Nisa, 2019; Prayitno, 2021).

CA memiliki keunggulan yaitu dapat menganalisis dan mengevaluasi informasi keuangan, membuat keputusan berdasarkan informasi dan merencanakan pelaksanaan keputusan yang dilaksanakan (Wardani \& Januarti, 2015; Widyanto \& Fitriana, 2016). CA dapat bertindak sebagai konsultan di bidang akuntansi, perpajakan, keuangan, pelaporan manajemen dan sistem informasi, serta memperoleh izin untuk mendirikan kantor jasa akuntansi selain jasa asuransi. CA juga dapat menandatangani laporan keuangan perusahaan (IAI, 2019). Kurikulum dari Fakultas sangat penting bagi mahasiswa dalam mempersiapkan diri untuk mengikuti ujian sertifikasi, salah satunya adalah ujian CA. Dengan memberikan mata kuliah pelengkap, siswa dapat mengikuti ujian CA. Hal ini dapat memengaruhi minat mahasiswa untuk mengikuti ujian sertifikasi akuntansi. Untuk memahami bagaimana FEB UKSW mempersiapkan mahasiswanya mengikuti ujian CA, maka silabus CA dibandingkan dengan mata kuliah yang ditawarkan FEB UKSW.

Penelitian yang sejalan minat mahasiswa akuntansi dalam pendidikan profesi akuntansi. Penelitiannya terhadap mahasiswa peserta PPAk di Kota Semarang (Universitas Diponegoro dan 
Universitas STIKUBANK menunjukkan bahwa faktor kualitas, karier, ekonomi, berpengaruh signifikan terhadap minat mengikuti PPAk, sedangkan faktor profesional dan faktor ekonomi tidak berpengaruh signifikan (Fajarsari, 2020). Penelitian lain terkait pengaruh motivasi terhadap minat mahasiswa akuntansi untuk mengikuti ujian Certified Public Accountant (CPA). Hasilnya adalah motivasi kareir dan ekonomi berpengaruh signifikan terhadap minat untuk mengikuti ujian CPA (Abidin \& Ervanto, 2015; Paramesti Ningrat \& Krisna Dewi, 2020). Motivasi kualitas, motivasi karier, dan motivasi ekonomi berpengaruh positif dan signifikan terhadap minat mahasiswa akuntansi untuk mengikuti pendidikan profesi akuntansi (Karyati \& Sukirno, 2016; Mahmudah, 2019; Surya B. \& Budiasih, 2019). Biaya pendidikan berpengaruh positif daan signifikan terhadap minat mahasiswa akuntansi untuk mengikuti pendidikan profesi akuntansi (Denziana \& Febriani, 2017; Febryanti A \& Suardana, 2018; Istanti et al., 2020; Rivandi \& Kemala, 2021).

Namun, penelitian lain menunjukkan hasil sebaliknya. Penghargaan finansial dan pertimbangan pasar kerja tidak berpengaruh signifikan terhadap minat mahasiswa akuntansi untuk berkarier menjadi akuntan publik (Dary \& llyas, 2019). Persepsi kontrol dan perilaku serta persepsi dan sikap mahasiswa tidak berpengaruh signifikan terhadap minat mahasiswa untuk mengikuti ujian sertifikasi CA (Wardani \& Januarti, 2015). Status akreditasi tidak ada perbedaan yang signifikan dan tidak berpengaruh terhadap minat mahasiswa untuk mengikuti pendidikan profesi akuntansi (Suprianto \& Nikmahi, 2016). Gender tidak memengaruhi minat mahasiswa akuntansi untuk berkarier menjadi akuntan public (Elfiswandi et al., 2019). Penelitian ini merupakan pengembangan dari penelitian Widyanto dan Rahmawati (2016) tentang pengaruh motivasi terhadap minat mahasiswa akuntansi mengikuti ujian sertifikasi CA. Hal yang membedakan dari penelitian sebelumnya dalam penelitian ini adalah adanya penambahan variabel biaya pendidikan, jenis kelamin, status akreditasi program studi, dan kartu anggota, tapi tidak ada variabel motivasi. Tujuan penelitian ini menganalisis minat mahasiswa akuntansi FEB UKSW mengikuti ujian sertifikasi chartered accountant (CA).

\section{Metode}

Jenis penelitian ini merupakan penelitian kuantitastif. Populasi dalam penelitian ini adalah mahasiswa Program Studi Akuntansi Universitas Kristen Satya Wacana yang masih aktif mengikuti perkuliahan. Teknik pengambilan sampel yaitu purposive sampling. Standar pengambilan sampel adalah untuk seluruh mahasiswa S1 akuntansi FEB UKSW yang mata kuliahnya mirip dengan mata kuliah ujian yang terdapat pada silabus CA. Alasan penentuan sampel adalah karena siswa yang pernah mengikuti kursus yang mirip dengan mata pelajaran dalam silabus CA memiliki pengetahuan yang cukup dalam teori dan praktik untuk mengikuti ujian sertifikasi CA. Menurut Sekaran (2006) jumlah sampel yang tersedia untuk penelitian berkisar antara 30-500, maka dalam penelitian ini dipilih 100 sampel sebagai responden penelitian. Data penelitian dianggap sebagai faktor penting dalam menentukan metode pengumpulan data. Jenis data yang digunakan dalam penelitian ini adalah data utama yang direview berupa biaya pendidikan, jenis kelamin, status akreditasi program studi, dan kartu anggota IAI untuk mengetahui minat mahasiswa akuntansi dalam mengikuti ujian sertifikasi CA. Data diperoleh dari mahasiswa akuntansi FEB UKSW yang menjadi sampel dalam penelitian ini, dan datanya diperoleh melalui angket kuesioner. Metode pengumpulan data menggunakan kuesioner. Karena data yang diperoleh berurutan, maka skala likert digunakan dalam penelitian ini. Dengan menggunakan skala ini, variabel dalam penelitian ini diubah menjadi indikator yang dapat diukur. Indikator terukur ini dapat digunakan sebagai titik awal untuk membuat pernyataan yang perlu dijawab oleh responden (Sekaran, 2006). Teknik analisis yang digunakan dalam penelitian ini adalah statistik deskriptif dengan bantuan program komputer Statistical Package for Social Science (SPSS) 20.Teknik statistik deskriptif adalah metode yang berhubungan dengan pengumpulan, pengolahan, penyajian, dan analisis data deskriptif kuantitatif. Data penelitian dianalisis menggunakan analisis data di antaranya adalah Uji validitas, Uji Reliabilitas, Uji Asumsi Klasik ( Uji Normalitas, Uji Multikolinearitas, Uji Heteroskedastisitas), dan Uji Hipotesis untuk menguji variabel yang saling berkaitan yaitu persamaan Regresi. 


\section{Hasil dan Pembahasan}

\section{Hasil Penelitian}

Berdasarkan hasil analisis, data yang diperoleh berkaitan dengan minat mahasiswa akuntansi feb uksw untuk mengikuti ujian sertifikasi chartered accountant (CA). Hasil analisis statistika deskriptif disajikan pada tabel 1.

Tabel 1. Analisis Statistik Deskriptif

\begin{tabular}{lcccc}
\hline \multicolumn{1}{c}{ Variabel } & Min & Max & Mean & Standar Deviasi \\
\hline Minat (Y) & 7,00 & 25,00 & 19,2700 & 3,33289 \\
Biaya Pendidikan (X1) & 17,00 & 40,00 & 29,5700 & 5,03775 \\
JenisKelamin (X2) & 1,00 & 2,00 & 1,6800 & 0,469 \\
Status Akreditasi Program Studi (X3) & 28,00 & 49,00 & 37,0700 & 4,25038 \\
KartuAnggota IAI (X4) & 12,00 & 25,00 & 18,8700 & 2,59235 \\
\hline
\end{tabular}

Sumber: Data primer yang telah diolah tahun 2021

Berdasarkan pengolahan data descriptive statistics di atas dapat dilihat bahwa pada tiap variable terdapat hasil penghitungan nilai min, max, mean, dan standar deviasi. Oleh karena itu, bisa dilihat bahwa biaya pendidikan, jenis kelamin, status akreditasi program studi, serta kartu anggota IAI berpengaruh terhadap minat mahasiswa akuntansi FEB UKSW untuk mengikuti ujian sertifikasi CA. Dari data tersebut variabel minat memiliki nilai min sebesar 7,00 , nilai max sebesar 25,00 , nilai mean 19,2700 , dan standar deviasi sebesar 3,33289. Variabel biaya pendidikan memiliki nilai min sebesar 17,00 , nilai max sebesar 40,00 , nilai mean 29,5700, dan standar deviasi sebesar 5,03775. Variabel jenis kelamin memiliki nilai min sebesar 1,00, nilai max sebesar 2,00, nilai mean 1,6800, dan standar deviasi sebesar 0,469 . Variabel status akreditasi program studi memiliki nilai min sebesar 28,00 nilai max sebesar 49,00, nilai mean 37,0700, dan standar deviasi sebesar 4,25038. Variabel kartu anggota IAI memiliki nilai min sebesar 12,00 , nilai max sebesar 25,00 , nilai mean 18,8700 , dan standar deviasi sebesar 2,59235. Dari data tersebut terlihat bahwa nilai standar deviasi lebih kecil daripada nilai ratarata. Artinya, data tersebut terdistribusi secara merata.

Hasil uji validitas memperlihatkan bahwa seluruh item pertanyaan memiliki korelasi positif dan lebih besar dari R-tabel. Hal ini berarti bahwa data yang dimiliki telah valid dan dapat dilakukan penelitian lebih lanjut. Dari pernyataan di atas variabel biaya pendidikan, jenis kelamin, status akreditasi program studi, dan kartu anggota IAI terbukti valid. Pengujian reliabilitas pada penelitian ini dilakukan dengan menggunakan metode alfa Cronbach. Pengujian keandalan dengan hasil di bawah 0,60 dianggap kurang baik. Semakin dekat koefisien keandalan dengan 1 akan semakin baik atau dapat dikatakan instrumen dikatakan reliabel apabila koefisien keandalannya 0,60 atau lebih. Hasil uji reliabilitas pada tabel di atas memperlihatkan bahwa seluruh variabel memiliki Cronbach Alpha yang masuk dalam kategori tinggi dan sangat tinggi. Hal ini berarti bahwa data yang dimiliki telah reliabel dan dapat dilakukan penelitian lebih lanjut.

Tabel 2. Uji Normalitas

\begin{tabular}{lrrrrrc}
\hline & \multicolumn{3}{c}{ Tests of Normality } & \multicolumn{3}{c}{ Shapiro-Wilk } \\
\hline & Statistic & df & Sig. & Statistic & df & Sig. \\
\hline $\begin{array}{l}\text { Unstandardized } \\
\text { Residual }\end{array}$ & 0,044 & 100 & $0,200^{*}$ & 0,986 & 100 & 0,361 \\
\hline
\end{tabular}

Sumber: Hasil pengolahan data kuesioner (2021)

Berdasarkan output di atas, dapat diketahui bahwa nilai signifikasi (Sig) pada Kolmogorov Smirnov sebesar 0,200. Nilai signifikansi (Sig) pada Shapiro-Wilk sebesar 0,361 karena signifikasi lebih dari 0,05. Dapat disimpulkan bahwa data yang dimiliki terdistribusi normal. 
Tabel 3. Uji Multikolinearitas

\begin{tabular}{lccc}
\hline \multirow{2}{*}{ Model } & \multicolumn{2}{c}{ Collinearity } & \multirow{2}{*}{ Keterangan } \\
\cline { 2 - 3 } & Tolerance & VIF & \\
\hline 1 (constant) & 0,868 & 1,323 & Bebas Multikolinearitas \\
Jenis Kelamin & 0,830 & 1,152 & Bebas Multikolinearitas \\
Biaya Pendidikan & 0,725 & 1,379 & Bebas Multikolinearitas \\
Status Akreditasi Program Studi & 0,755 & 1,325 & Bebas Multikolinearitas \\
Kartu Anggota IAl & \multicolumn{3}{c}{ Sumber: Data primer yang telah diolah tahun 2021 }
\end{tabular}

Uji multikolinearitas dilakukan untuk mengetahui apakah tiap-tiap variabel independen yang digunakan sama sekali tidak berhubungan satu dengan yang lain sehingga dapat dikatakan bahwa tidak terjadi multikolinieritas. Untuk mengatahui terjadi atau tidaknya multikolinearitas, maka dilihat melalui tolerance value atau Variance Inflation Factor. Setelah dilakukan pengujian dengan SPSS 20, dihasilkan nilai VIF dan tolerence. Dari tabel di atas dapat dilihat bahwa setiap variabel independen memiliki nilai Variance Inflation Factor (VIF) berada sekitar 1 sampai 10. Demikian juga hasil tolerance value mendekati 1 atau di atas 0,1. Hal ini berarti bahwa antar variabel independen tidak memiliki hubungan yang kuat dan signifikan. Dengan kata lain, pada model regresi tidak terdapat masalah multikolinearitas.

Tabel 4. Uji Heteroskedastisitas

\begin{tabular}{|c|c|c|c|c|c|c|}
\hline \multicolumn{7}{|c|}{ Coefficients $^{\mathrm{a}}$} \\
\hline \multicolumn{2}{|c|}{ Model } & \multicolumn{2}{|c|}{ Unstandardized Coefficients } & \multirow{2}{*}{$\begin{array}{c}\begin{array}{c}\text { Standardized } \\
\text { Coefficients }\end{array} \\
\text { Beta } \\
\end{array}$} & \multirow[t]{2}{*}{$\mathbf{T}$} & \multirow[t]{2}{*}{ Sig. } \\
\hline & & B & Std. Error & & & \\
\hline \multirow[t]{5}{*}{1} & (Constant) & 0,672 & 2,137 & & 0,314 & 0,754 \\
\hline & $\operatorname{LnX1}$ & 0,023 & 0,018 & 0,073 & 0,240 & 0,332 \\
\hline & $\operatorname{LnX} 2$ & 0,035 & 0,046 & 0,083 & 0,761 & 0,448 \\
\hline & $\operatorname{LnX3}$ & 0,013 & 0,060 & 0,027 & 0,223 & 0,824 \\
\hline & LnX4 & 0,065 & 0,097 & 0,078 & 0,668 & 0,506 \\
\hline
\end{tabular}

a. Dependent Variable: LN_RES

Sumber: Data primer yang telah diolah (2021)

Pada tabel hasil output di atas terlihat bahwa nilai signifikasi ke empat variabel independen yang telah di Ln dengan LN_RES lebih dari 0,05. Dengan demikian, dapat disimpulkan bahwa pada model regresi tidak ada masalah heteroskedastisitas atau dapat dikatakan bahwa model regresi bebas heteroskedastisitas. Sesuai dengan data pengamatan melalui kuesioner yang telah diolah menggunakan SPSS 25 for windows version tentang 1 (satu) dependent variable berupa minat mahasiswa mengikuti ujian sertifikasi $\mathrm{CA}(\mathrm{Y})$; dan 3 (tiga) independent variable yang terdiri dari biaya pendidikan (X1),jenis kelamin (X2) status akreditasi program studi (X3), dan kartu anggota IAI (X4), dapat diperoleh hasil kalkulasi dari regresi linear berganda yang dapat disajikan pada tabel 5 .

Tabel 5. Regresi Linear berganda

\begin{tabular}{|c|c|c|c|c|}
\hline \multirow[t]{2}{*}{ Model } & \multicolumn{2}{|c|}{ Unstandarized } & \multirow[t]{2}{*}{$\mathbf{T}$} & \multirow[t]{2}{*}{ Sig } \\
\hline & B & Std. Error & & \\
\hline (Constant) & 12,095 & 2,621 & 4,614 & 0,000 \\
\hline Pendidikan (X1) & 0,217 & 0,070 & 1,384 & 0,003 \\
\hline JenisKelamin (X2) & $-0,537$ & 0,541 & $-0,993$ & 0,323 \\
\hline Status Akreditasi Program Studi(X3) & 0,112 & 0,068 & 1,847 & 0,007 \\
\hline
\end{tabular}




\begin{tabular}{|c|c|c|c|c|}
\hline \multirow[t]{2}{*}{ Model } & \multicolumn{2}{|c|}{ Unstandarized } & \multirow[t]{2}{*}{$T$} & \multirow[t]{2}{*}{ Sig } \\
\hline & B & Std. Error & & \\
\hline KartuAnggota IAI (X4) & $-0,084$ & 0,112 & $-0,743$ & 0,459 \\
\hline
\end{tabular}

Data di atas menunjukkan analisis regresi yang diperoleh dari aplikasi SPSS, jadi Persamaan yang dapat ditarik adalah sebagai berikut:

$$
\begin{aligned}
& Y=a+b 1 X 1+b 2 \times 2+b 3 X 3+b 4 X 4+e \\
& Y=12,095+0,217 X 1+(-0,537 \times 2)+0,112 \times 3+(-0,084 X 4)
\end{aligned}
$$

Tabel 6. Uji Signifikan Parameter Individual (Uji t)

\begin{tabular}{lccccc}
\hline \multirow{2}{*}{ Model } & \multicolumn{2}{c}{ Unstandarized } & \multirow{2}{*}{ T } & Sig \\
\cline { 2 - 3 } & B & Std. Error & & \\
\hline 1 (Constant) & 12,095 & 2,621 & 4,614 & 0,000 \\
Biaya Pendidikan (X1) & 0,217 & 0,070 & 1,384 & 0,003 \\
JenisKelamin (X2) & $-0,537$ & 0,541 & $-0,993$ & 0,323 \\
Status Akreditasi Program Studi(X3) & 0,112 & 0,068 & 1,847 & 0,007 \\
KartuAnggota IAI (X4) & $-0,084$ & 0,112 & $-0,743$ & 0,459 \\
\hline
\end{tabular}

Sumber: Data primer yang telah diolah tahun 2021

Variabel Biaya pendidikan terbukti berpengaruh positif karena nila B sebesar 0,217 dan signifikansi $0,003<0,05$. Artinya variabel biaya pendidikan berpengaruh positif dan signifikan terhadap minat mahasiswa akuntansi FEB UKSW untuk mengukuti ujian sertifikasi CA. Variabel jenis kelamin terbukti tidak menimbulkan perbedaan yang signifikan nila B sebesar $-0,537$ dan signifikansi $0,323>0,05$. Artinya variabel jenis kelamin berpengaruh negatif dan tidak signifikan terhadap minat mahasiswa akuntansi FEB UKSW untuk mengukuti ujian sertifikasi CA. Variabel Status akreditasi program studi terbukti berpengaruh positif karena nila B sebesar 0,112 dan signifikansi 0,007<0,05. Artinya variabel status akreditasi program studi berpengaruh positif dan mempengaruhi secara signifikan terhadap minat mahasiswa untuk mengikuti ujian sertifikasi CA. Variabel kartu anggota IAI terbukti berpengaruh negatif karena nila B sebesar $-0,084$ dan signifikansi $0,459<0,05$. Artinya, variabel kartu anggota IAI berpengaruh negatif dan tidak memengaruhi secara signifikan terhadap minat mahasiswa dalam mengikuti sertifikasi CA.

Tabel 7.Uji Signifikan Simultan (Uji F)

\begin{tabular}{ccccccc}
\hline & Model & Sum of Squares & Df & Mean Square & F & Sig. \\
\hline \multirow{4}{*}{1} & Regression & 111,116 & 4 & 27,779 & 4,444 &, 002 \\
& Residual & 593,794 & 95 & 6,250 & & \\
& Total & 704,910 & 99 & & & \\
\hline
\end{tabular}

Sumber: Berdasarkan data primer yang diolahtahun 2021

Tabel di atas memperlihatkan bahwa angka pada F-hitung adalah 4,444 dengan angka F-tabel dalam tabel distribusi $F$ untuk probabilitas 0,05 yaitu 2,70 . Jadi, 4,444 $>2,70$ memiliki arti bahwa $F$ hitung lebih besar dari F-tabel. Sehingga dapat disimpulkan bahwa variabel $X$ yaitu biaya pendidikan, jenis kelamin, status akreditasi program studi, serta kartu anggota IAI berpengaruh positif dan signifikan terhadap variabel $\mathrm{Y}$ yaitu minat mahasiswa untuk mengikuti ujian sertifikasi $C A$. Berdasarkan hasil penelitian biaya pendidikan, jenis kelamin, status akreditasi program studi, serta kartu anggota IAI berpengaruh positif dan signifikan terhadap variabel $Y$ yaitu minat mahasiswa untuk mengikuti ujian sertifikasi CA. Temuan pertaman, biaya pendidikan memengaruhi minat mahasiswa akuntansi FEB UKSW untuk mengikuti ujian sertifikasi CA. Biaya pendidikan menjadi kendala mahasiswa dalam mengikuti ujian sertifikasi akuntansi CA karena biaya mahal. Hal ini 
diperkuat dengan penelitian yang menyatakan bahwa biaya pendidikan menimbulkan dampak negatif terhadap minat mahasiswa akuntansi untuk mengikuti pendidikan profesi akuntansi. Biaya pendidikan mahal mejadi kendala bagi sebagian mahasiswa (Widiyani \& Badera, 2019). Hasil penelitian ini telah membuktikan biaya pendidikan memang mahal tapi mahasiswa berminat untuk mengikuti ujian sertifikasi CA supaya bisa meningkatkan kemampuannnya dalam menjadi akuntan yang bersertifikat CA. Semakin mahal biaya pendidikan minat mahasiswa akuntansi semakin turun untuk mengikuti pendidikan profesi akuntansi (Marta Permana \& Suartana, 2018; Surya B. \& Budiasih, 2019; Widiyani \& Badera, 2019).

Temuan kedua, jenis kelamin berpengaruh negatif dan tidak signifikan terhadap minat mahasiswa akuntansi FEB UKSW untuk mengikuti ujian sertifikasi CA. Temuan ini diperkuat dengan temuan penelitian sebelumnya yang menyatakan pengaruh negatif mengenai minat mahasiswa untuk mengikuti ujian sertifikasi CA (Dary \& Ilyas, 2019; Hapsoro \& Hendrik, 2018). Jika ditinjau dari segi jenis kelamin, perbedaan jenis kelamin tidak menghalangi seseorang untuk berkarier di bidang profesi akuntansi. Faktor perbedaan jenis kelamin di era dewasa ini sudah tidak lagi menjadi perbedaan yang signifikan antara laki-laki dan perempuan. Hal ini dibuktikan dengan tidak signifikannya perbedaan antara laki-laki dan perempuan dalam memiliki minat untuk megikuti ujian sertifikasi CA. Anggapan bahwa perempuan era lama yang tidak bisa bebas dalam menentukan jalan hidupnya sendiri sudah mulai terkikis oleh waktu. Hasil yang ditemukan dalam penelitian ini mendukung bahwa perbedaan jenis kelamin memiliki minat yang sama besarnya dalam mengikuti sertifikasi CA.

Temuan ketiga, status akreditasi program studi berpengaruh positif dan memengaruhi secara signifikan terhadap minat mahasiswa untuk mengikuti ujian sertifikasi CA. Hal ini sejalan dengan hasil penelitian dari Surifah, Mustiati, Syaifullah, \& Bowo (2016) yang menemukan bahwa status akreditasi program studi memiliki pengaruh terhadap minat mahasiswa akuntansi untuk mengikuti ujian sertifikasi CA. Contohnya, nilai akreditasi UNGGUL menunjukkan bahwa kualitas pendidikan yang dilaksanakan di program studi akuntansi dan mutu pelayanan pendidikan sangat baik. Status Akreditasi program studi merupakan acuan yang sangat penting bagi program studi akuntansi karena menunjukkan kualitas lulusan dan pendidikan yang sudah sangat baik. Temuan lain juga menyatakan akreditasi program studi berpengaruh positif dan signifikan terhadap minat mahasiswa akuntansi untuk memilih program studi akuntansi (Kamal \& Rahmadiane, 2017).

Temuan keempat, Syarat untuk mengikuti ujian sertifikasi CA adalah menjadi anggota Ikatan Akuntan Indonesia (IAI). Kepemilikan kartu anggota IAI berpengaruh negatif mungkin disebabkan oleh faktor bahwa mahasiswa merasa belum siap untuk mengikuti ujian. Mereka belum memenuhi syarat untuk mengikuti ujian sertifikasi CA. Namun, di sisi lain mereka sadar akan keuntungankeuntungan yang didapat jika sudah menjadi anggota IAI, antara lain: profesi yang diraih diakui secara nasional bahkan internasional. Dengan profesi yang disandang dapat menimbulkan rasa percaya diri dan dihargai secara baik oleh masyarakat serta memiliki kesempatan untuk bekerja dengan para ahli di bidang lain dll. Dalam hal ini mahasiswa belum siap mengikuti ujian sertifikasi CA meskipun telah memiliki kartu anggota IAI karena berbagai macam faktor yang tidak termasuk dalam penelitian ini.

\section{Simpulan}

Berdasarkan hasil penelitian, minat mahasiswa akuntansi FEB UKSW untuk mengikuti ujian sertifikasi CA dapat dipengaruhi oleh biaya pendidikan berpengaruh positif dan signifikan terhadap minat mahasiswa akuntansi FEB UKSW untuk mengikuti ujian sertifikasi CA. Jenis kelamin tidak berpengaruh signifikan terhadap minat mahasiswa akuntansi FEB UKSW untuk mengikuti ujian sertifikasi CA. Status Akreditasi Program Studi berpengaruh positif dan signifikan terhadap minat mahasiswa akuntansi FEB UKSW untuk mengikuti ujian sertifikasi CA dan kartu anggota IAI tidak berpengaruh signifikan terhadap minat mahasiswa akuntansi FEB UKSW untuk mengikuti ujian sertifikasi CA. Penelitian selanjutnya diharapkan memperluas obyek penelitian dan melakukan kajian yang lebih rinci agar informasi yang berkaitan dengan ujian sertifikasi CA bisa tersampaikan dengan 
baik. Selain itu, untuk penelitian selanjutnya tambahkan variabel yang relevan dengan keadaan saat ini agar penelitian bisa berkembang dan beragam.

\section{Daftar Pustaka}

Abidin, A. Z., \& Ervanto, A. D. (2015). Pengaruh Motivasi terhadap Minat Mahasiswa Akuntansi Mengikuti Ujian Certified Public Accountant ( CPA ). Jaffa, 03(1), 55-68. http://journal.trunojoyo.ac.id/jaffa/article/view/957.

Dary, A. W., \& Ilyas, F. (2019). Pengaruh Gender, Penghargaan Finansial, dan Pertimbangan Pasar Kerja terhadap Minat Mahasiswa Akuntansi untuk Berkarier menjadi Akuntan Publik dan Non Akuntan Publik. Jurnal Akuntansi, 7(1), 51-60. https://doi.org/10.33369/j.akuntansi.7.1.5160.

Denziana, A., \& Febriani, R. F. (2017). Pengaruh Motivasi, Persepsi Biaya Pendidikan, dan Lama PendidikantTerhadap Minat Mahasiswa Akuntansi untuk Mengikuti Pendidikan Profesi Akuntansi (PPAk) (Studi Kasus pada Perguruan Tinggi di Bandar Lampung). Jurnal Akuntansi Dan Keuangan, 8(2), 55-66. https://doi.org/10.36448/jak.v8i2.946.

Elfiswandi, E., Melmusi, Z., \& Chanigia, C. (2019). Analisis Faktor-Faktor yang Memengaruhi Minat Mahasiswat terhadap Pemilihan Karier sebagai Akuntan Publik (Studi Kasus pada Mahasiswa Jurusan Akuntansi di Kota Padang). JIM UPB (Jurnal IImiah Manajemen Universitas Putera Batam). JIM UPB (Jurnal Ilmiah Manajemen Universitas Putera Batam), 7(1), 38. https://doi.org/10.33884/jimupb.v7i1.890.

Fajarsari, H. (2020). Pengaruh Motivasi dan Persepsi terhadap Minat Mahasiswa Mengikuti Pendidikan Profesi Akuntansi ( PPAK ) di Kota Semarang. COMPETITIVE Jurnal Akuntansi Dan Keuangan, 4(2), 113. https://doi.org/10.31000/c.v4i2.2532.

Febryanti A, P. A. B., \& Suardana, K. A. (2018). Pengaruh Motivasi dan Pengetahuan UU No.5 Tahun 2011 Pada Minat Mahasiswa Akuntansi Mengikuti PPAK. E-Jurnal Akuntansi, 22(5), 357. https://doi.org/10.24843/eja.2018.v25.i01.p14.

Gretha Steenkamp. (2014). How Pre-Admission Characteristics Affect the Performance of CTA Students at a South African University. Journal Of Economic And Financial Sciences, 7(2), 283 - 298. https://doi.org/10.4102/jef.v7i2.141.

Hapsoro, D., \& Hendrik, D. T. (2018). Analisis Faktor-Faktor yang Memengaruhi Minat Mahasiswa akuntansi Berkarier sebagai Akuntan Publik (Studi Kasus terhadap Mahasiswa Akuntansi STIE YKPN Yogyakarta). Akuntansi Dewantara, 2(2), 142-156.

IAI. (2019). Fungsi dan Posisi CA (p. Diakses pada tanggal 6 April 2021).

Istanti, E., Nusantoro, J., \& Sari, G. P. (2020). Pengaruh Tingkat Pemahaman Akuntansi, Persepsi Biaya terhadap Niat untuk Mengambil Sertifikasi Profesi Chartered Accountant (CA ) Dengan Motivasi Sebagai Variabel Moderasi ( Studi Kasus pada Mahasiswa Akuntansi di Universitas Muhammadiyah Metro ). Jurnal Akuntansi AKTIVA, 1(2), 191-209. https://doi.org/10.24127/akuntansi.v1i2.552.

Kamal, B., \& Rahmadiane, G. D. (2017). Pengaruh Persepsi, Akreditasi Prodi, dan Promosi terhadap Keputusan Memilih Program Studi Akuntansi pada Politeknik Harapan Bersama. Jurnal Inspirasi Bisnis Dan Manajemen, 1(2), 145. https://doi.org/10.33603/jibm.v1i2.866.

Karyati, K., \& Sukirno, S. (2016). Pengaruh Citra Merek dan Persepsi Biaya Pendidikan terhadap Minat Melanjutkan Studi. Jurnal Pendidikan Akuntansi Indonesia, 14(1). https://doi.org/10.21831/jpai.v14i1.11367.

Mahmudah, N. (2019). Analisis Faktor-Faktor yang Memengaruhi Minat Mahasiswa STEI SEBI Jurusan Akuntansi Syariah terhadap Profesi Akuntan Publik. JURNAL AKUNTANSI DAN KEUANGAN ISLAM, 2(1), 83-100. https://doi.org/10.35836/jakis.v2i1.54.

Marta Permana, I. M. B. A., \& Suartana, I. W. (2018). Pengaruh Motivasi Kualitas, Motivasi Karir, Motivasi Ekonomi, Motivasi Sosial, Biaya Pendidikan pada Minat Mengikuti PPAk. E-Jurnal Akuntansi, 25, 214. https://doi.org/10.24843/eja.2018.v25.i01.p09.

Mongilala, J. F. (2021). Faktor-Faktor yang Memengaruhi Minat Mahasiswa Akuntansi Mengikuti 
Ujian Sertifikasi Chartered Accountant (CA) (Studi Kasus pada Politeknik Negeri Manado). Jurnal Akuntansi Profesi, 12(1), 77. https://doi.org/10.23887/jap.v12i1.33824

Nisa, S. (2019). Mahasiswa Akuntansi untuk Mengambil Profesi Chartered Accountant (CA) Pada Universitas Islam Swasta Di Kota Medan. Jurnal Riset Akuntansi Multiparadigma (JRAM), 6(1), 64-73.

Paramesti Ningrat, I. A. A., \& Krisna Dewi, L. G. (2020). Pengaruh Motivasi, Lingkungan Keluarga, Biaya Pendidikan pada Minat Mahasiswa Mengikuti Pendidikan Profesi Akuntansi. E-Jurnal Akuntansi, 30(7), 1684. https://doi.org/10.24843/eja.2020.v30.i07.p06.

Prayitno, J. A. (2021). Faktor yang Memengaruhi Minat Mahasiswa Akuntansi dalam Memperoleh Sertifikasi Profesional Akuntansi di Indonesia (Chartered Accountant) (Studi Kasus Mahasiswa Akuntansi Semester Akhir pada Universitas dengan Prodi Akuntansi Berakreditasi A dan B yang berlokasi di Jakarta). COMPETITIVE Jurnal Akuntansi Dan Keuangan, 5(2), 91. https://doi.org/10.31000/competitive.v5i2.4248.

Rivandi, M., \& Kemala, E. R. (2021). Pengaruh Motivasi, Biaya Pendidikan dan Lama Pendidikan terhadap Minat Mahasiswa Akuntansi Mengikuti Pendidikan Akuntansi (PPAk) di Universitas Dharma Andalas. Jurnal Ekonomi Dan Bisnis Dharma Andalas, 23(1), 94-108. https://doi.org/10.47233/jebd.v23i1.177.

Sekaran, U. (2006). Metodologi dan Penelitian. Salemba Empat.

Setyawan, S., \& Iswanaji, C. (2019a). Pengaruh Motivasi Akuntan terhadap Minat untuk Memperoleh Gelar Chartered Accountant ( CA ) di Wilayah Yogjakarta. Jurnal Riset Akuntansi Dan Keuangan, 7(2), 327-342.

Setyawan, S., \& Iswanaji, C. (2019b). Pengaruh Motivasi Akuntan terhadap Minat untuk Memperoleh Gelar Chartered Accountant (CA) di Wilayah Yogjakarta. Jurnal Riset Akuntasi Dan Keuangan, 7(2), 327 - 342. https://doi.org/10.17509/jrak.v7i2.16855.

Suprianto, E., \& Nikmahi, M. (2016). Analisis Faktor-Faktor yang Memengaruhi Minat Mahasiswa Akuntansi Untuk Mengikuti Pendidikan Profesi Akuntansi Ditinjau Dari Gender dan Status Akreditasi Program Studi. Jurnal Akuntansi Indonesia, 2(1), 17. https://doi.org/10.30659/jai.2.1.17-25.

Surya B., I. G. A. D., \& Budiasih, I. G. A. N. (2019). Pengaruh Motivasi dan Persepsi Biaya Pendidikan pada Minat Mahasiswa Mengikuti Pendidikan Magister Akuntansi. E-Jurnal Akuntansi, 28(2), 929. https://doi.org/10.24843/eja.2019.v28.i02.p06.

Wahyuni, S., ' Z., \& Natariasari, R. (2014). Pengaruh Motivasi terhadap Minat Mahasiswa Akuntansi untuk Mengikuti Pendidikan Profesi Akuntansi (Ppak). Jurnal Online Mahasiswa Fakultas Ekonomi Universitas Riau, 1(1), 246-258.

Wardani, G. A. S., \& Januarti, I. (2015). Niat untuk Mengambil Chartered Accountant dengan Theory Of Planned Behavior. Jurnal Akuntansi Dan Auditing, 12(2), 140-159. https://doi.org/10.14710/jaa.v12i2.13863.

Widiyani, N. L. I. A., \& Badera, I. D. N. (2019). Pengaruh Motivasi, Biaya Pendidikan dan Lama Masa Studi pada Minat Mahasiswa Mengikuti PPAk. E-Jurnal Akuntansi, 29(1), 188. https://doi.org/10.24843/eja.2019.v29.i01.p13.

Widyanto, E. A., \& Fitriana, R. (2016). Pengaruh Motivasi terhadap Minat Mengikuti Ujian Chartered Accountant ( CA ) Indonesia. Jurnal Eksis, 12(1), $3214-3345$. 